\title{
Musical Sensitivity on Trained and Untrained Vocalist: A study of English phonological awareness
}

\author{
Yune Andryani Pinem, Nur Makkie Perdana Kusuma \\ STTKD School of Aerospace Technology \\ Yogyakarta, Indonesia \\ j.andryani@gmail.com; yune.andryani@sttkd.ac.id
}

\author{
Antonius Gathut Bintarto Triprasetyo \\ Department of Music Indonesian Institute of the Arts \\ Yogyakarta, Indonesia \\ bintarto_853@yahoo.com
}

\begin{abstract}
Music and language acquiring spots may be different in the brain yet share the same sound production. Skills to acknowledge music is beneficial to produce musical arts while the ability to recognize phonology in English leads to not only native-like pronunciation but also word-class identification and implicature. This study attempts to look at how musical sensitivity affects phonological awareness of both trained and untrained vocalists. The objects of this research are elements of music (rhythm and pitch) that reflected English phonology (rhythm and intonation). Toward two groups of trained and untrained vocalists, the instrument of evaluation which includes 46 tests in listening for each subject (music and phonology) was given. The test is to measure participants' ability to duplicate sound based on the instruction given. Data for this study - score from both subjects - were analyzed by using variance and interpretation. From the sound production of all respondents, the problem occurs on English pronunciation as the effects of elements of rhythm and pitch in misunderstanding, accent and robotic utterance. The effect of music on untrained $(x 2)$ vocalist toward phonology $(y)$ seems to outperform trained (x1) vocalist by more than 10 percent. However, both are able to give above 50 percent contribution on English phonology. By this, musical practice on rhythm and pitch is recommended to be conducted on English pronunciation class.
\end{abstract}

Keywords—musical sensitivity; phonological awareness; nature acquisition; nurture acquisition

\section{INTRODUCTION}

Music and language are not only two different subjects but also different in acquisition and processing inside the brain (left cerebral for language, right for music). However, besides difference mentioned, there are similarities between both in an acquisition which are the usage of speech organ in producing a sequence of digitized sounds (Jackendoff, 2009), neural mechanism particularly brain activation and improvisation toward melodic unfamiliarity in nearly identical functional brain area (Deguchi et al., 2012; Talamini, Grassi, Toffalini, Santoni, \& Carretti, 2018; Yu et al., 2017) and perception in term of awareness (Patel, 2011; Zeromskaite, 2014). Further, the correlation between two subjects can be also found on the technical mechanism which is observable using functional magnetic resonance imaging (fMRI) in processing language semantics (Bever \& Chiarello, 2009). Both domains seem to have intriguing correlations that are possible to give effect in another way around.
The result of previous researches on the correlation between both domains explains how specific teaching material on musical skills can strengthen non-native students' level of English pronunciation. Nevertheless, musical aptitude in this case melodic and rhythmic analysis is not only limited to affect pronunciation, but also a semantic process through auditorymotor integration ( $\mathrm{Yu}$ et al., 2017) and dictation skills (Talamini et al., 2018) among early childhood of $3-4$ years old (Lorenzo, Herrera, Hernandez-Candelas, \& Badera, 2014) and in young learner around $13-15$ years old or under 18 years old.

How musicians outperform non-musician in language extends to various aspects of pitch change detection on sentence prosody (Deguchi et al., 2012), being differentiated between nature and nurture in the case of the level of the competence, people who are skilled and not skilled on music have different dominance on cerebral (Bever \& Chiarello, 2009). As it is cited in Bever and Chiarello (2009), musically experienced listeners recognize simple melodies better in the right ear than the left, while the reverse is true for naïve listeners. Hence, contrary to previous reports, music perception supports the hypothesis that the left hemisphere is dominant for analytic processing and the right hemisphere for holistic processing. It needs the researcher to analyze the different groups regarding sensitivity level (nature and nurture) in responding to English pronunciation practices.

Phonological awareness on a particular language is started from the process of listening as the stimulation, which is continued to the process of cognition in our brain. In this cognition process, the human starts to identify and categorize sounds to be functioned to speak, read, even to write. A baby of his first day of life may not understand the mother's lullaby, but still, the baby will fall asleep. This describes us that music may give us insight into how the language sounds to us before we understand it. The baby only focuses on repetitive vocal performance using emotional content on rhythmic and phonemic patterns and consistencies. As seen also in longitudinal experimental research to use the activity guide of "Desperter Musical" to improve language development in students (Lorenzo et al., 2014).

In the process of speaking, identifying and categorizing sounds would be included in the step of phonemic which gives meaning to the utterances so that the message delivering can be conducted effectively. To utter, one uses the technique of imitation, which is to copy sounds that have been heard previously and then the repetition would be made as close as 
possible to make it clear for the interlocutors. Based on this understanding, abundant studies have been conducted to make the connection between the skills of speaking with the skill of listening. The research of Pinem reveals the strong relationship among those two, which results in the score of regression 3.314 for the students of high school. It is not arguable that those two factors support the assessment of listening and speaking classes (Pinem, 2014).

Generally, in considering music and language, science differentiates them psychologically. The language will take the position as a process which is gained by the left-side of the brain, and music would be in the right one. With this differentiation results from the different functions. Music, especially on vocal, is sliced with the language on the level of sound production (related to one of the language areas, Phonological sound) facilitated by speaking cord. By employing the modern approach using technologies, the role of music in teaching languages related to sound has been researched many times (Deguchi et al., 2012; Demirezen, 2015; Sun et al., 2018; Yu et al., 2017). The result of this interdisciplinary indicates that the relationship between these two does exist and influence one another. Furthermore, this relationship also influences other aspects of language learning. The referred aspects can be found in the tonal language (Astorga-Cabezas, 2015), as it is stated that Native tone language experience has been linked with alterations in the production and perception of pitch in language, as well as with the brain response to linguistic and non-linguistic tones. However, it also influences to the non-tonal language as it is positively proven to the children who have Phonological dyslexia deficiency (Giuliano, Pfordresher, Stanley, Narayana, \& Wicha, 2011), the effect of phonological awareness for the pre-elementary students on reading and writing (Degé \& Schwarzer, 2011; Loui, Kroog, Zuk, Winner, \& Schlaug, 2011). Regarding exposure (training and such a kind) and talent or nature, both of them reveal the variable or manner on one's skill in music. In the case of language learning, the exposures of target language using music and film are the most dominant factors for the learners of the Eastern part of Indonesia where sound and text can be found simultaneously (Pinem, 2016).

Music and language are two activities that connect, which have proven the hypothesis of music by nature and nurture on children showing positive relation to second language learning (Talamini et al., 2018). Moreover, consistencies (Jackendoff, 2009) proposed that all language teachers in all schools in China should be competent also in music training so that they are capable of employing the music environment for achieving learning goals for all pupils effectively and efficiently. Encouraging music in language classes can potentially improve foreign language pronunciation, receptive phonology and reading skills (Zeromskaite, 2014). OPERA's hypothesis was introduced to explain the relationship between music and language (Patel, 2011). This is the acronym of Overlap, Precision, Emotion, Repetition, and Attention. It describes us about how language comprehension might be benefited from music exposure in the way that music increases our enhancement to study language effectively.

The shared character between language and music is that the Phonological structure should be rhythmical and 'easy listening' to convey a particular message. Based on that fact, a sound arrangement in music is based on language phonology. On the other hand, on music, sound arrangement on music is based on pitch tonal. The question that may arise is that, is the pitch tonal characters identical with the concept in language. The question can be answered due to the existence of fact that prosodic contour in language and melody is decreasing in the end. Therefore, the sound is the object shared for both subjects (music and phonology). In language, the element of sound including stress, rhythm, and intonation which becomes focus on music especially for a vocalist appears with various functions both in phonemic and pragmatic principle.

However, language and music also possess radical differences. One of them is that language is constructed based on words arranged systematically based on sentence syntactic, this is known as a syntactic category. The study on the syntactic category includes a class of words, in which words have a particular function which is acceptable. Some syntactic categories are formed to become sentences and those are arranged to form paragraphs about the idea that would be transferred and understood by the readers or listeners. Music, on the other hand, is arranged based on individual tone and the structure of prolongation. The language syntax contents agreement, case, reflexivity and wh-words. Even in the construction of the words, there is a system that forms words so that they would have meaning.

All previous studies mentioned above expose similarities between both variables and how they correlate in general. However, to look at them specifically into the particular element of rhythm and intonation remains untouched. Especially, in English, both elements can be phonemic and pragmatic. Later, to measure how musical sensitivity particularly on these elements affects English phonological awareness on similar elements is worth observing. Therefore, this study is conducted to add more insight on the effect of music toward language.

\section{METHODS}

Two groups of respondents consists of trained vocalist $(n=15)$ and untrained vocalist $(n=15)$. They are classified based on musical aptitude scoring including (1) attending musical lesson at school, (2) attending training course, (3) having vocal training, (4) having instrumental training, (5) joining musical grading test and (6) winning prizes in musical contest (Pei, Wu, Xiang, \& Qian, 2016) with range of point from one as the lowest to six as the highest. Those who are qualified as trained vocalist (variable Y1) will at least get more than 3 score on this and on the other side those who are not qualified will have lessen score.

In order to know participants' level in musical sensitivity from trained (variable $\mathrm{x} 1$ ) and untrained (variable $\mathrm{x} 2$ ) vocalists and English phonological awareness (variable y), two types of instruments are carefully premeditated. First instrument is musical test which is created by a specialized vocal teacher from one of reliable art institutions in Indonesia, compiled with years of experience on it. Second instrument is an English phonological test which is created covering musical model of Stannard (Stannard, 1953). Both tests are formulated in mirroring carrying two elements of rhythm and intonation in form of sound model. This is the test where participants can listen toward the sound model with some pause enabling them to duplicate and record their own production. Each result of production is then scored by qualified 
teacher from each subject. Score collected from musical test is considered as data for variable $\mathrm{x}$ and score from phonological test is considered as data for variable $\mathrm{y}$.

Statistical process is applied to measure the effect of several dependent variables on several independent variables. In this case, the study looks at how (1) trained vocalist as category gives impact on (a) musical score and (b) phonological score. The second category is (2) untrained vocalist to be measured over same variables of (a) musical score and (b) phonological score. Later, musical score will be seen as one determining factor to give impact on phonological score on both categories of vocalist. In this case analysis of variance is taken place to find the value of regression and significance..

\section{FINDING AND DISCUSSION}

In contrast to $\mathrm{Yu}$ et al. (2017), who highlights semantic as the major area affected by the link between music and language, (Deguchi et al., 2012) proclaims that generating melody in an untrained musician as a result of their response over unfamiliar auditory is majorly presented in melodies and phrases. In his case, generativity mentioned occurs more in complex sound structures (phonology) - even in jabberwocky - rather than in informational content (semantics). This simply occurs as result of brain activation in nearly identical functional brain area for language and music.

\section{A. Elements of Music on Language}

Some suprasegmental features of stress, rhythm and intonation are generally presented in any languages. In English, skills on stress and intonation enhance understanding in communication (Zhang \& Yin, 2009). In a native, these features may occur naturally in a conversation. However, in a non-native of second or foreign language learners, this can be only obtained by systematical training and exercise (Yurtbasi, 2012).

Sharing similarity, these features in phonology can be reflected in elements of music. To look at component structure on both domains using the comparison method may give parallel insights to employ each element toward one another. Regarding the object of this study which is more to linguistics, no depth discussion is necessarily done to specify elements of music - which is considered wider and broader - to avoid this study turning into different directions.

\section{1. (Lexical and Sentence) Stress in English and Rhythm in Music}

Recent studies conducted have ensured the position of the importance of English stress and rhythm proficiency on ESL/EFL learners to have an intelligible speech in the target language. Fail to do so results in poor pronunciation and accented speech (Demirezen, 2012) or misunderstanding (Arslan, 2013). Therefore, some teaching techniques are utilized to give significant improvement on stress and intonation such as the performing of E-Learning class design to deliver this topic content (Yangklang, 2013).

The problem on this element can be found on word stress over some homograph words with different word classes as in production of 'present' and 'record' (N) and 'present' and 'record' (V). This problem is the potential to cause misunderstanding on reference words. Another problem is related to a local accent. Some participants from central Java ethnic overly use Javanese /dh/ sound and unable to exactly duplicate English diphthong. Thus, the imitating process results in accented English which in the greater case can also lead to misunderstanding.

\section{Sentence Intonation and Pitch}

In case of intonation where stress can fall not only in premier or secondary stress but can also fall in the tertiary (unstressed) syllable, ESL/EFL learners are required to employ this feature in order to have humanistic less robotic utterance in normal target-language conversation. In order to solve problem occurred in the non-native learner, cultural-value sharing of wisdom in the form of proverbs can be an effective material used to teach segmental and suprasegmental features in L2 circumstance.

Analyzing one's sound sensitivity and the impacts when he is struggling to comprehend the pronunciation of a particular language is interesting to conduct. In producing sound to deliver the message, sometimes one needs to do step in intonation (up and down), but in a particular circumstance, he needs to do glide (up and down) which possesses different structures and techniques of the production. The change of pitch, up and down, is conducted to give stress on words' content which is sometimes given in the end of the sentence. A statement and a question in English have different pitch changing; those are down for the first and up for the second one. Besides, the stress on words with one syllable and more than one syllable has differences, which is gliding for the first and stepping for the second.

From the production recorded by respondents, the problem occurs in intonation on a longer $y / n$ question sentence. This type of sentence should be increasing at the end. However, while the model starts the production in relatively low pitch at the beginning, some respondents do it in the opposite (in a relatively higher pitch). This phenomenon is resulted by the word-by-word reading style of the respondent. Instead of producing sentences by function, respondents tend to produce it per word. Thus, the recording sounds less human. Further, pitch production which is different from the sound model also eliminates pragmatic meaning as in raising intonation on whquestion. Wh-question normally ends in falling intonation. However, for a pragmatic reason, raising its ending can give meaning that the speaker is asking for confirmation after the first question. Failing to raise intonation in wh-question surely violates the pragmatic meaning of confirming the response and turns it into an original question. Incompetency on the respondent to duplicate raising intonation on wh-question for confirming purpose is derived from their nature capability on the first language (Indonesian) which also habitually performs wh-question in falling intonation

\section{B. Musical Sensitivity toward Phonological Awareness Among Trained and Untrained Vocalist}

Suprasegmental features of stress, rhythm and intonation are generally presented in any languages. In a native, this may occur naturally in a conversation. However, in a non-native of second or foreign language learner, this can be only obtained by 
a systematical training and exercise (Yurtbasi, 2012). As shown in Table I.

TABLE I. DIFFERENCES IN MUSICAL AND PHONOLOGICAL PRODUCTION ON TRAINED AND UNTRAINED VOCALIST

\begin{tabular}{|l|c|c|c|c|c|}
\hline & $R(\%)$ & Sig. F & $\begin{array}{c}\text { Mean } \\
\text { Square }\end{array}$ & $\boldsymbol{t}$. & $P$-Value \\
\hline Trained Vocalist Musical Score & 42 & $0.009 *$ & 0.15 & 2.36 & $0.03 *$ \\
\hline $\begin{array}{l}\text { Trained Vocalist Phonological } \\
\text { Score }\end{array}$ & 15 & 0.143 & 0.23 & 0.75 & 0.14 \\
\hline $\begin{array}{l}\text { Trained Vocalist Musical Score } \\
\text { and Phonological Score }\end{array}$ & 52 & $0.002 *$ & 1.85 & 3.74 & $0.002 *$ \\
\hline Untrained Vocalist Musical Score & 38 & $0.013 *$ & 0.34 & 2.52 & $0.025 *$ \\
\hline $\begin{array}{l}\text { Untrained Vocalist Phonological } \\
\text { Score }\end{array}$ & 39 & $0.012 *$ & 0.34 & 2.36 & $0.034 *$ \\
\hline $\begin{array}{l}\text { Untrained Vocalist Musical Score } \\
\text { and Phonological Score }\end{array}$ & 64 & $0.0002 *$ & 4.36 & 5.43 & $0.0001 *$ \\
\hline
\end{tabular}

From regression and variance analysis on both groups of trained and untrained vocalist, it can be concluded that:

1. Musical aptitude on 6 elements proposed by Pei (Pei et al., 2016) has been proved to have a significant effect on musical score represented by the value of $\mathrm{F}$ and $\mathrm{P}$. The effect of musical aptitude on trained vocalist reaches almost $50 \%$ to determine their competence in music as seen on their score on musical imitating test. However, this result cannot be seen on the result of their phonological score. With low value of $\mathrm{R}$, there is no significance in $\mathrm{F}$ and $\mathrm{P}$ value. This means that musical aptitude on trained vocalist is not a guarantee for a good phonological imitating test. Yet, significance can be seen on the correlation of musical competence in form of the score and phonological proficiency. The effect of musical score reaches more than $50 \%$ over the phonological score with significance on $\mathrm{F}$ and $\mathrm{P}$ value.

2. Over untrained vocalist it can be seen that among 3 variables tested on regression, the most influencing on untrained vocalists' phonological awareness is their ability to musical sensitivity. Even though the variable of musical aptitude also gives a positive impact on musical and phonology competence, the values are only half from the effect of musical score toward the phonological score.

3. The fact that untrained vocalist outperforms trained vocalist on the effect of musical over phonological score, this can be only explained by the tendency of higher mean square on untrained vocalist. It means that respondent from untrained vocalist group has better competence in English phonology in advance. There is no pre-observation on this variable, thus no conclusion can be drawn yet on this matter

\section{CONCLUSION}

Looking at how music is associated to language has been a focus of language acquisition, medical study and psychology. In many ways, ability to acknowledge as well as producing melodic structure in music in certain extent is able to give improvement on language in term of semantics and phonology, which is beneficial in helping reading and speaking. In phonology, which focuses particularly on sound, the correlation between both fields is reflected on the elements of rhythm and intonation, which is always problematic in non-native speaker. Respondents' native language is a dominant factor which suitably gives impact on the error. Observing both elements from both subjects, especially by scoring, comparing and analyzing the result is one way to measure the quality of this correlation. Musical aptitude of trained vocalist has been proven to give effect mostly to musical competence. This phenomenon cannot be seen on untrained vocalist. However, from this study, it is proven one more time how musical sensitivity effect phonological awareness to both trained and untrained vocalist more than $50 \%$. Therefore, in order to enhance the result of English pronunciation, it is decent to recommend some space for musical training particularly on rhythm and intonation. Earlier studies about music link toward language have been done using neural and valid tool approach and involving expensive facilities in many other countries, which is not presented in this study. Due to lack of time and facility, this research relies on expertise from both fields to do the evaluation and scoring. Further observation to look at these subjects relation in the future can be done by using meticulous instrument and proper technology. After all, a similar study toward Indonesian social factors is still rare to none.

\section{REFERENCES}

Arslan, R. Ş. (2013). Non-native pre-service english language teachers achieving intelligibility in English: Focus on lexical and sentential stress. Procedia - Social and Behavioral Sciences. 70, 370-374. doi: 10.1016/j.sbspro.2013.01.074

Astorga-Cabezas, E. D. (2015). The relationship between listening proficiency and speaking improvement in higher education: Considerations in assessing speaking and listening. Higher Learning Research Communications, 5(2), 34-56. doi: 10.18870/hlrc.v5i2.236

Bever, T. G., \& Chiarello, R. J. (2009). Cerebral Dominance in Musicians and Nonmusicians. Journal of Neuropsychiatry, 21(1), 94-97. doi: 10.1176/appi.neuropsych.21.1.94

Degé, F., \& Schwarzer, G. (2011). The effect of a music program on phonological awareness in preschoolers. Frontiers in Psychology, 2, 124. doi: 10.3389/fpsyg.2011.00124

Deguchi, C., Boureux, M., Sarlo, M., Besson, M., Grassi, M., Schon, D., \& Colombo, L. (2012). Sentence pitch change detection in the native and unfamiliar language in musicians and non-mucisians: Behavioral, electrophysiological and psychoacoustic study. Brain Research, 1455, 75-89. doi: 10.1016/j.brainres.2012.03.034

Demirezen, M. (2012). Demonstration of problems of lexical stress on the pronunciation Turkish English teachers and teacher trainees by computer. Procedia - Social and Behavioral Sciences. 46, 3011-3016. doi: 10.1016/j.sbspro.2012.05.606

Demirezen, M. (2015). The Perception of primary stress in initially extended simple sentence. A demonstration by computer in foreign language teacher training. Procedia - Social and Behavioral Sciences, 186, 11151121. doi: 10.1016/j.sbspro.2015.04.136 
Giuliano, R. J., Pfordresher, P. Q., Stanley, E. M., Narayana, S., \& Wicha, N. Y. Y. (2011). Native experience with a tone language enhances pitch discrimination and the timing of neural responses to pitch change. Frontiers in Psychology, 2, 146. doi: 10.3389/fpsyg.2011.00146

Jackendoff, R. (2009). Parallels and nonparallels between language and music. Music Perception: An Interdisciplinary Journal, 26(3), 195-204. doi: 10.1525/mp.2009.26.3.195

Lorenzo, O., Herrera, L., Hernández-Candelas, M., \& Badea, M. (2014). Influence of music training on language development. A longitudinal study. Procedia - Social and Behavioral Sciences, 128, 527-530. doi: 10.1016/j.sbspro.2014.03.200

Loui, P., Kroog, K., Zuk, J., Winner, E., \& Schlaug, G. (2011). Relating pitch awareness to phonemic awareness in children: Implications for tonedeafness and dyslexia. Frontiers in Psychology, 2, 111. doi: 10.3389/fpsyg.2011.00111

Patel, A. D. (2011). Why would musical training benefit the neural encoding of speech? The OPERA hypothesis. Frontiers in Psychology, 2, 142. doi: 10.3389/fpsyg.2011.00142

Pei, Z., Wu, Y., Xiang, X., \& Qian, H. (2016). The effects of musical aptitude and musical training on phonological production in foreign languages. English Language Teaching, 9(6), 19-29. doi:10.5539/elt.v9n6p19

Pinem, Y. A. (2014). The correlation between listening and speaking among high school students. ELTICS: Journal of English Language Teaching and English Linguistics, 1(1), 12-23.

Pinem, Y. A. (2016, April). Extra-lingual factors facilitating east Indonesian students' perception on producing long-short vowel of English. Paper presented at Conference: Language in the Online and Offline World 5: The Amplitude, Petra Christian University.

Stannard, A. W. (1953). Living english speech. Longman.

Sun, Y., Lu, X., Ho, H. T., Johnson, B. W., Sammler, D., \& Thompson, W. F. (2018). Syntactic processing in music and language: Paralle abnormalities observed in congenital amusia. NeuroImage: Clinical, 19, 640-651. doi: 10.1016/j.nicl.2018.05.032

Talamini, F., Grassi, M., Toffalini, E., Santoni, R., \& Carretti, B. (2018). Learning a second language: Can music aptitude or music training have a role? Learning and Individual Differences, 64, 1-7. doi: 10.1016/j.lindif.2018.04.003

Yangklang, W. (2013). Improving English stress and intonation pronunciation of the first year students of Nakhon Ratchasima Rajabhat University through an e-learning. Procedia - Social and Behavioral Sciences, 91, 444-452. doi: 10.1016/j.sbspro.2013.08.442

Yu, M., Xu, M., Li, X., Chen, Z., Song, Y., \& Liu, J. (2017). The shared neura basis of music and language. Neuroscience, 357, 208-219. doi: 10.1016/j.neuroscience.2017.06.003

Yurtbasi, M. (2012). Teaching sentential intonation through proverbs. Procedia - Social and Behavioral Sciences, 46, 4323-4327. doi: 10.1016/j.sbspro.2012.06.250

Zeromskaite, I. (2014). The potential role of music in second language learning: A review article. Journal of European Psychology Students, 5(3), 78-88. doi: $10.5334 /$ jeps.ci

Zhang, F., \& Yin, P. (2009). A Study of pronunciation problems of English learners in China. Asian Social Science, 5(6), 141-146. doi: 10.5539/ass.v5n6p14 